\title{
Gerenciamento do portfolio de projetos: um estudo exploratório
}

\author{
Project Portfolio Management: an exploratory study \\ on the challenges of its implementation and results
}

\author{
Henrique Gonçalves de Castro' \\ Marly Monteiro de Carvalho²
}

\begin{abstract}
Resumo: Os principais conceitos de gerenciamento de portfolio de projetos (PPM - Project Portfolio Management) ainda têm pouca penetração nas empresas. Apesar do desenvolvimento acadêmico, as técnicas de PPM são novas para as organizações, particularmente no Brasil, onde este tema ainda é emergente, dado que os primeiros estudos foram realizados no início da década de 90 e vêm se tornando mais frequentes na década atual. Dada a lacuna de dados empíricos sobre a implementação do PPM e de seus resultados, este artigo visa investigar as principais práticas de PPM adotadas, o estágio de implementação e a relação entre as práticas e os resultados obtidos. Neste artigo foi realizado um levantamento exploratório, com 31 respondentes de diferentes organizações. Os principais resultados deste estudo indicam que o PPM ainda é pouco presente nas organizações e, quando é, não apresenta medidas claras dos resultados obtidos com este processo.
\end{abstract}

Palavras-chave: Administração de projetos. Gerenciamento do portfolio de projetos.

\begin{abstract}
The main concepts of project portfolio management, or just PPM, are not widely spread through organizations, especially in project the area. In spite of the academic development, PPM techniques are new for most of the companies, mainly in Brazil where this is an emergent topic since it started in the 90,s but it has grown fast in the current decade. Due to the lack of empirical data about PPM implementation and its results, this paper aims to identify the main PPM practices adopted, its implementation stages, and the relationship between those practices and the obtained benefits. This study presents an exploratory survey completed by 31 respondents, who are executives from different organizations. The main research results indicate that PPM is still rarely present in organizations and, whenever it is present, it does not show clear results.
\end{abstract}

Keywords: Project management. Project Portfolio Management.

\section{Introdução}

O campo de gestão de portfolio tem origem na década de 50, com o desenvolvimento da base para a teoria moderna de portfolio, no âmbito de negócios. Nas décadas de 80 e 90, estabeleceram-se as bases para o gerenciamento do portfolio de projetos (Project Portfolio Management - PPM) (DYE; PENNYPACKER, 1999; DE REYCK et al., 2005).

A literatura de análise e o planejamento do portfolio de projetos cresceram nos anos 90 , à semelhança do que ocorrera com o portfolio de negócio nos anos 70 e 80. Neste período, foi desenvolvido o plano agregado de projetos (WHEELWRIGHT; CLARK, 1992) e realizados diversos estudos sobre o portfolio no âmbito de desenvolvimento de novos produtos e da área de pesquisa e desenvolvimento (COOPER; EDGETT; KLEINSCHMIDT, 1997a, b, 1998, 1999, 2001a, b), ao mesmo tempo em que as empresas americanas começam a reconhecer que os princípios da gestão de projetos poderiam ser utilizados tanto para a implementação quanto na operacionalização de planos estratégicos (KERZNER, 2002).

Ao longo das últimas décadas, as áreas de conhecimento - gestão de projetos e gestão de portfolio - começam, de fato, a integrarem-se, o que tem sido denominado na literatura de gerenciamento de portfolio de projetos ou, simplesmente a sigla, PPM (Project Portfolio Management). O PPM tornou-se um fator significativo no sucesso das estratégias de longo prazo das organizações e está relacionado ao papel dos altos executivos e tomadores de decisões-chave que devem validar os investimentos relevantes, além de formular e implementar metas

\footnotetext{
${ }^{1}$ Mestre em Engenharia Naval e Oceânica, Escola Politécnica, Universidade de São Paulo - USP

2 Professora Livre-docente do Departamento de Engenharia de Produção, Escola Politécnica, Universidade de São Paulo - USP, Av. Prof. Almeida Prado, Trav. 2, n. 128, CEP 05508-900, E-mail: marlymc@usp.br
} 
e objetivos. No entanto, as técnicas estudadas são novas para as organizações, seus resultados não foram exaustivamente testados e ainda não há consenso entre os executivos em relação à importância do PPM (COOPER; EDGETT; KLEINSCHMIDT 1997b, 1999, 2001b; DYE; PENNYPACKER 1999; LEVINE, 1999; ARCHER; GHASEMZADEH, 1999; DIETRICH; LEHTONEN, 2005).

No contexto brasileiro, Kruglianskas (1992) foi um dos primeiros autores a analisar a aplicação das técnicas de portfolio na gestão de projetos, dando a elas o objetivo de estruturar os projetos em um contexto harmônico, considerando que os recursos da empresa são limitados e os projetos devem alinhar-se com os objetivos da empresa. Na visão de Rabechini Jr., Maximiano e Martins (2005), a complexidade inerente ao PPM faz com que poucas organizações tenham acesso a suas práticas e, consequentemente, a suas potencialidades.

Observa-se que, apesar do desenvolvimento acadêmico, ainda há pouca evidência das práticas de gestão de portfolio nas organizações (JEFFERY; LELIVELD, 2004; CASTRO; CARVALHO, 2006; CARVALHO; RABECHINI Jr., 2005). Engwall e Jerbrant (2003) reforçam a necessidade de estudos comparativos entre diferentes contextos de multiprojeto, diferentes tipos de portfolio e diferentes restrições ambientais, pois entendem que há pouco conhecimento sobre quais fatores da gestão de portfolio de projetos são específicos do contexto e quais são universais. Neste ambiente de multiprojeto, vários projetos são conduzidos em paralelo, consumindo recursos da mesma fonte em um contexto altamente político, com uma constante competição por prioridade, pessoas, atenção e recursos.

Neste sentido este artigo visa investigar as principais práticas de PPM adotadas, o estágio de implementação e a relação entre as práticas e os resultados obtidos. Dada a lacuna de dados empíricos, optou-se por um levantamento exploratório realizado em 31 organizações.

Este artigo está estruturado em 6 seções. A próxima seção apresenta a síntese do quadro teórico sobre o gerenciamento de portfolio de projetos. Em seguida, apresenta-se a abordagem metodológica utilizada na pesquisa. As seções 4 e 5 apresentam os resultados obtidos e as discussões e análises. Finalmente, a seção 6 traz as conclusões e limitações do estudo.

\section{Quadro teórico}

O tema central é portfolio de projetos, para o qual existem várias traduções para o português, como porta-fólio, portofólio e portfólio. Alguns autores também utilizam o termo carteira, que possui o mesmo significado. Para facilitar o acesso a este estudo, optou-se pelo termo original em inglês, portfolio, e a sigla PPM, que representa Project Portfolio
Management, para designar o gerenciamento do portfolio de projetos.

Para a construção do quadro conceitual (framework) foi feito um levantamento da literatura, no qual se destacaram cinco modelos. Três destes modelos foram desenvolvidos na década de 90 por Wheelwright e Clark (1992), Cooper, Edgett e Kleinschmidt (1997) e Archer e Ghasemzadeh (1999) e são referência para os estudos de PPM no Brasil e no mundo. Rabechini Jr., Maximiano e Martins (2005), com base nestes três modelos, propôs um modelo de PPM que foi aplicado em uma empresa brasileira prestadora de serviços de interconexão eletrônica. Recentemente, o Project Management Intitute, PMI (2006), também desenvolveu um modelo PPM.

Para fazer uma análise comparativa dos modelos, foram agrupadas cinco dimensões que aparecem com maior frequência nestes modelos de PPM. As dimensões desta análise foram estruturadas de forma a facilitar a análise e compreensão dos modelos estudados: definição dos critérios de decisão, definição dos recursos disponíveis, classificação dos projetos, alocação dos recursos e controle do portfolio.

\subsection{Critérios de decisão}

Para Cooper, Edgett e Kleinschmidt (1997b), é necessário integrar, de forma harmônica, as decisões de portões (gates) e de portfolio para minimizar os conflitos entre as decisões dos portões e as revisões de portfolio, pois, no primeiro caso, as decisões são em tempo real e individual em cada projeto, enquanto, no segundo, são tomadas periodicamente, considerando-se todos os projetos. Além disso, muitos modelos de PPM utilizam muitas informações, que sobrecarregam os executivos das organizações que, consequentemente, não conseguem utilizá-las da forma adequada. Isto leva a uma necessidade de definir claramente os critérios que serão utilizados para a tomada de decisão. Combe (1998) complementa, reforçando que o desafio para as organizações é difundir a estratégia, tanto de crescimento quanto de melhoria contínua, de forma clara o suficiente para permitir que os critérios de priorização de projetos sejam bem assimilados pelos gerentes e patrocinadores de projetos.

Vários autores abordam o tema de critérios de decisão (ARDITI; SINGH, 1991; HAMILTON, 2002; JOLLY, 2003; MAHDI; ALRESHAID, 2005; BERTOLINI; BRAGLIA; CARMIGNANI, 2006; PADOVANI et al. 2008). No entanto, há significativa variação no elenco de critérios adotado de acordo com o tipo de projeto e o tipo de organização.

Hamilton (2002), por exemplo, identificou três critérios de decisão principais, que depois são desdobrados em subcritérios, quais sejam: rentabilidade do produto, satisfação do cliente e gama de produtos. Os critérios relacionados à rentabilidade do produto são 
desdobrados em termos de design para a manufatura, design para o mercado, baixa intensidade de mão de obra, capital e custo de material, e curto time to market. Com relação à satisfação dos clientes, o autor sugere flexibilidade do produto, atender às especificações técnicas ou excedê-las, preços competitivos, valor agregado e segurança de produto e facilidade de instalação e funcionamento. Finamente, com relação ao desenvolvimento de uma gama de produtos os itens observados são o mercado e a análise de produtos concorrentes, e garantir a aceitabilidade do produto, enfatizando aspectos relacionados ao meio ambiente e esteticamente agradável produto.

Já Jolly (2003) parte de uma lista de 32 critérios disponíveis na literatura para os projetos de tecnologia, dos quais 16 são relacionados à competitividade e 16 à atratividade. Essa lista de 32 critérios foi priorizada por um grupo de executivos de importantes multinacionais. Os critérios mais importantes encontrados por Jolly (2003), relativos à atratividade são: impacto da tecnologia sobre questões concorrenciais, o volume de mercado aberto proporcionado pela tecnologia, a extensão de aplicações fornecidas abertas pela tecnologia, o gap de desempenho vis-à-vis alternativas tecnológicas e intensidade competitiva. Já com relação aos critérios relativos à competitividade julgados mais importantes são: desenvolvimento de competências de equipes, distância entre a tecnologia e os negócios centrais (core business) da empresa, time to market relativo à concorrência, capacidade de financiamento, pesquisa aplicada, e a reação do mercado ao design proposto pela empresa.

\subsection{Definição dos recursos disponíveis}

Os executivos e gerentes responsáveis pelo gerenciamento de portfolio de projetos devem conhecer as restrições da organização e indicar necessidades de ampliação da capacidade e redução de algumas destas restrições. Aquilo que uma empresa deseja fazer nem sempre é o que ela pode fazer. Normalmente, o maior obstáculo está na disponibilidade e qualidade dos recursos necessários. A maioria dos gerentes não pensa em termos de pontos fortes e fracos, e, por isso, preocupa-se mais com o que deveria fazer do que com o que pode realmente fazer. No entanto, não faz parte do gerenciamento de portfolio de projetos definir e gerenciar as atividades necessárias para adequar a capacidade organizacional (KESSLER; CHAKRABARTI, 1996; KERZNER, 2002; ENGWALL; JERBRANT, 2003).

\subsection{Classificação dos projetos}

A forma de classificar os projetos varia bastante entre os autores. Para Archibald (1992) apud Archer e Ghasemzadeh (1996), as principais classes são: (i) projetos comerciais e governamentais realizados sob contrato; (ii) projetos de pesquisa, desenvolvimento de produtos, engenharia e marketing; (iii) projetos de desenvolvimento e construção de capital facilities (ex. construção de grandes prédios); (iv) projetos de sistemas de informação; (v) projetos de gerenciamento (ex. reengenharia); e (vi) projetos de manutenção. Já Wheelwright e Clark (1992), que concentraram seus estudos nos projetos de desenvolvimento de produtos e processos, propõem cinco diferentes tipos: (i) projetos derivativos; (ii) projetos de plataforma; (iii) projetos de ruptura; (iv) projetos de $\mathrm{P} \& \mathrm{D}$; e (v) projetos de aliança e parceria. Em um estudo mais recente, Shenhar (2001) propõe a classificação dos projetos com base no nível de incerteza tecnológica. Cooper, Edgett e Kleinschmidt (1997b) entendem que todos os projetos competem pelos mesmos recursos, independente do seu tipo ou classificação e, portanto, devem fazer parte de um mesmo portfolio, para que os conflitos entre os projetos sejam minimizados durante a implementação. Já Dye e Pennypacker (2000) entendem que apenas os projetos semelhantes devem ser comparados e, para isso, deve haver uma definição da quantidade de recursos a ser alocada em cada categoria (WHEELWRIGHT; CLARK, 1992; ARCHER; GHASEMZADEH, 1996). Os autores reforçam que a metodologia mais adequada para uma determinada classe não necessariamente é a mais adequada para outras classes. Para Archer e Ghasemzadech (1996), cada organização deve considerar, para cada classe, a metodologia a que melhor se adapta e que considera os atributos mais importantes para a decisão de seleção.

\subsubsection{Avaliação dos projetos}

Os seguintes atributos de avaliação devem ser considerados: retorno econômico, análise de risco, valor estratégico, técnicas de análise de custo-benefício e pesquisa de mercado. $\mathrm{O}$ uso de cada uma das técnicas depende da necessidade de cada organização e da fase dos projetos, mas deve-se estabelecer um conjunto comum de técnicas para que os projetos possam ser comparados e para que os projetos que não atendam a um conjunto mínimo de requisitos sejam eliminados antes que o estágio de seleção tenha início (MCFARLAN, 1981; MATHESON; MENKE, 1994; ARCHER; GHASEMZADEH, 1999; LEVINE, 1999; DIETRICH; LEHTONEN, 2005). Jeffery e Leliveld (2004) mostram que pouco mais da metade das organizações utiliza o ROI como critério de avaliação e priorização dos projetos, o que é um número muito baixo, considerando a importância desta análise em uma seleção adequada de investimentos. Para piorar, apenas $25 \%$ das organizações medem o ROI alcançado após a efetivação dos projetos. Para McFarlan (1981), três dimensões são importantes na análise do risco 
de cada projeto: (i) o tamanho dos projetos, que deve ser considerado de forma comparativa ao tamanho médio dos projetos conduzidos pela organização; (ii) a experiência com a tecnologia que será utilizada; e (iii) a estrutura do projeto, que considera a organização da documentação e volatilidade do escopo. Na avaliação de projetos em andamento, devem ser levados em consideração possíveis replanejamentos dos projetos e o custo de paralisar ou cancelar projetos antes da finalização.

Para Cooper, Edgett e Kleinschmidt (1998), a maioria das organizações utiliza diversos métodos, dos quais os mais utilizados estão no Quadro 1, que apresenta um resumo das vantagens e desvantagens de cada um dos métodos.

\subsubsection{Seleção e priorização dos projetos}

A seleção do portfolio envolve a comparação simultânea de um número de projetos em uma dimensão específica para obter a sequência desejada dos projetos. (ARCHER; GHASEMZADEH, 1999).

Esta avaliação e a decisão, que devem ser realizadas em comitê para que reflita o interesse das várias áreas da organização, são atividades de extrema importância, uma vez que, na maioria das organizações, há mais projetos identificados do que capacidade para implementá-los (GREMILLION; PYBURN, 1983; WHEELWRIGHT;
CLARK, 1992; ARCHER; GHASEMZADEH, 1999; DYE; PENNYPACKER, 1999; KENDALL; ROLLINS, 2003). Apesar da importância desta dimensão, verificou-se pouco progresso na obtenção de um framework que considere simultaneamente todos os diferentes critérios (ARCHER; GHASEMZADEH, 1996). Os projetos devem ser priorizados de acordo com sua importância e contribuição para a estratégia da organização, de forma comparativa aos demais projetos, tanto os que estão sendo avaliados como aqueles que estão em andamento. A prioridade de cada projeto pode mudar a cada nova avaliação, de modo que reflita as mudanças no ambiente.

No trabalho de Archer e Ghasemzadeh (1996), diversos métodos são comparados de acordo com as características dos projetos e do portfolio e algumas características de suporte, conforme sintetizado no Quadro 2.

\subsection{Alocação dos recursos}

A alocação matricial de recursos passou a ser uma prática comum, na qual vários projetos compartilham os mesmos recursos, alocados pelas áreas funcionais e demais stakeholders. Esta prática favorece o jogo político e os conflitos na alocação dos recursos, mas torna-se ainda mais complexa em grandes organizações com dezenas ou centenas de projetos, em que, segundo os autores, nenhum executivo tem condições de tomar as decisões efetivamente em cada

Quadro 1. Vantagens e desvantagens dos métodos (COOPER; EDGETT; KLEINSCHMIDT, 1998).

\begin{tabular}{|c|c|c|}
\hline Métodos & Vantagens & Desvantagens \\
\hline Abordagens estratégicas & $\begin{array}{l}\text { Método com melhor desempenho, } \\
\text { apresentando as seguintes vantagens: } \\
\text { alinhamento com a estratégia, projetos de } \\
\text { alto valor são selecionados, gastos refletem } \\
\text { a estratégia, o método se ajusta ao estilo } \\
\text { de decisão, é bem compreendido e fácil de } \\
\text { utilizar. }\end{array}$ & $\begin{array}{l}\text { Este método não é bem utilizado na } \\
\text { análise individual de projetos nem permite } \\
\text { um bom balanceamento entre os projetos. }\end{array}$ \\
\hline Financeiro & $\begin{array}{l}\text { Apesar de ser o mais popular, não há } \\
\text { nenhuma vantagem evidente deste método. }\end{array}$ & $\begin{array}{l}\text { Apesar de ser o mais popular, é o método } \\
\text { com maior número de desvantagens: não } \\
\text { oferece balanceamento, não promove a } \\
\text { utilização das janelas de oportunidade de } \\
\text { mercado, não são compreendidos pelos } \\
\text { gerentes, não consideram os elementos- } \\
\text { chave de tomada de decisão, entre outros. }\end{array}$ \\
\hline Pontuação & $\begin{array}{l}\text { Excelente no ajuste ao estilo de decisão } \\
\text { e na seleção de projetos de alto valor. } \\
\text { Também apresenta bons resultados no } \\
\text { alinhamento à estratégia. }\end{array}$ & $\begin{array}{l}\text { Não é fácil de utilizar e não restringe a } \\
\text { quantidade à capacidade da organização. }\end{array}$ \\
\hline Diagramas de bolhas & $\begin{array}{l}\text { Apesar da pouca utilização mostra bom } \\
\text { alinhamento estratégico, efetividade, } \\
\text { facilidade na utilização e seleciona projetos } \\
\text { de alto valor. }\end{array}$ & $\begin{array}{l}\text { Não restringe a quantidade à capacidade } \\
\text { da organização, é lento e os gastos não } \\
\text { refletem a estratégia. }\end{array}$ \\
\hline
\end{tabular}


um dos projetos. Algumas organizações alocam um gerente com a jurisdição sobre todos os projetos, outras criam comitês específicos para alocação de recursos. (SHARPE; KEELIN, 1998; CLELAND, 1999; ENGWALL; JERBRANT, 2003). Em vez de aumentar a ênfase em planejamento, relatórios de progresso e reuniões de acompanhamento, Engwall e Jerbrant (2003) recomendam que todo o sistema organizacional de gestão deve ser revisto desde sua raiz. A estratégia e a alocação de recursos nos projetos devem estar intimamente conectadas. Enquanto os recursos não são efetivamente alocados, a estratégia é apenas um conjunto de palavras em um documento. Se a estratégia é focar em certos mercados, produtos ou tecnologias, então a maioria dos recursos deve estar focada nos mesmos mercados, produtos ou tecnologias
(COOPER; EDGETT; KLEINSCHMIDT, 1997b; CLELAND, 1999; DYE; PENNYPACKER, 2000)

\subsection{Controle do portfolio}

Para Dye e Pennypacker (2000), a gestão de múltiplos projetos é complexa, pois contempla uma grande variedade de tipos de projetos, com características muito diferentes: pequenos e grandes, técnicos e não técnicos, estratégicos e operacionais, o que aumenta consideravelmente o risco de insucesso. Neste ambiente, os executivos não conseguem acompanhar de perto todos os projetos e precisam delegar a gestão dos projetos para os níveis inferiores, o que demanda atenção dos gerentes, quanto aos recursos disponíveis, quanto ao uso de ferramentas apropriadas de controle de projetos.

Quadro 2. Análise dos métodos em face das características (adaptado de ARCHER; GHASEMZADEH, 1996).

\begin{tabular}{|c|c|c|c|c|c|c|c|c|c|c|c|c|c|c|c|c|}
\hline \multirow[t]{2}{*}{ Método } & \multicolumn{10}{|c|}{ Característica do projeto/portifolio } & \multicolumn{6}{|c|}{ Característica de suporte } \\
\hline & 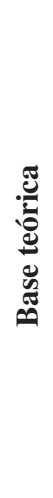 & 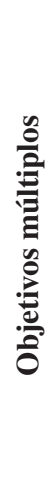 & 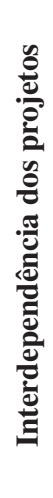 & 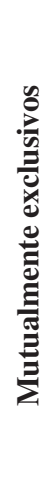 & 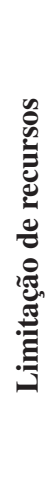 & 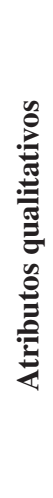 & 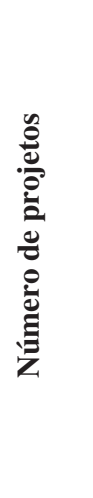 & 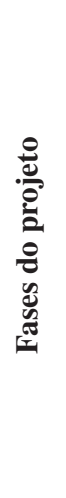 & 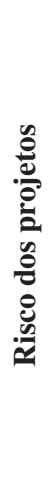 & 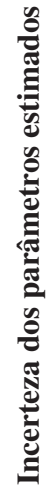 & 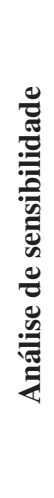 & 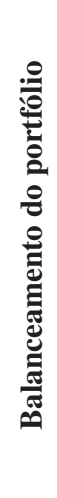 & 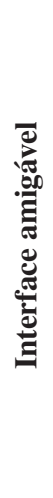 & 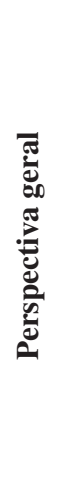 & 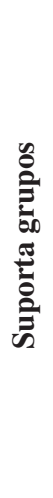 & 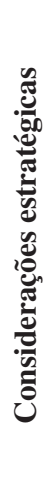 \\
\hline Comparativos & & & & & & & & & & & & & & & & \\
\hline Q-Sort & - & - & - & - & $\mathrm{S}$ & $\mathrm{S}$ & P-M & - & - & - & - & - & - & - & $\mathrm{S}$ & $\mathrm{S}$ \\
\hline Comparação de pares & - & - & - & - & $\mathrm{S}$ & $\mathrm{S}$ & $\mathrm{P}$ & - & - & - & - & - & - & - & - & - \\
\hline Pontuação & - & $\mathrm{S}$ & - & - & S & $\mathrm{S}$ & P-G & - & - & - & - & - & - & - & - & - \\
\hline Processo analítico hierárquico & $\mathrm{S}$ & $\mathrm{S}$ & - & - & $\mathrm{S}$ & $\mathrm{S}$ & $\mathrm{P}-\mathrm{M}$ & - & - & - & $\mathrm{S}$ & - & $\mathrm{S}$ & S & $\mathrm{S}$ & - \\
\hline Benefícios & & & & & & & & & & & & & & & & \\
\hline Retorno econômico & $\mathrm{S}$ & - & - & - & - & - & P-G & $\mathrm{S}$ & - & - & $\mathrm{S}$ & - & - & - & - & - \\
\hline Análise de risco & $\mathrm{S}$ & $\mathrm{S}$ & - & - & - & - & P-G & $\mathrm{S}$ & $\mathrm{S}$ & $\mathrm{S}$ & $\mathrm{S}$ & - & - & - & - & - \\
\hline Pesquisa de mercado & & & & & & & & & & & & & & & & \\
\hline Pesquisa de mercado & - & $\mathrm{S}$ & - & - & - & $\mathrm{S}$ & $\mathrm{P}$ & - & - & - & - & - & - & - & - & $\mathrm{S}$ \\
\hline Planejamento estratégicc & & & & & & & & & & & & & & & & \\
\hline Matriz de portifolio & - & $\mathrm{S}$ & - & - & $\mathrm{S}$ & S & $\mathrm{P}-\mathrm{M}$ & & $S$ & - & - & $S$ & $S$ & $S$ & $\mathrm{~S}$ & S \\
\hline Modelagem cognitiva & - & $\mathrm{S}$ & - & - & - & $\mathrm{S}$ & M-G & - & - & - & - & $\mathrm{S}$ & & $\mathrm{S}$ & $\mathrm{S}$ & $\mathrm{S}$ \\
\hline Análise de Cluster & $\mathrm{S}$ & S & - & - & - & S & M-G & - & - & - & - & - & - & $S$ & - & S \\
\hline Desestruturada & & & & & & & & & & & & & & & & \\
\hline Perfis & - & S & - & - & - & - & P-G & - & - & - & - & - & - & S & - & - \\
\hline Otimização & & & & & & & & & & & & & & & & \\
\hline 0-1 inteiros LP & $\mathrm{S}$ & & S & S & $\mathrm{S}$ & - & $\mathrm{P}-\mathrm{M}$ & $\mathrm{S}$ & - & - & S & - & - & - & - & - \\
\hline Programação de metas & $\mathrm{S}$ & $\mathrm{S}$ & $\mathrm{S}$ & $\mathrm{S}$ & $\mathrm{S}$ & - & P-G & $\mathrm{S}$ & - & - & $\mathrm{S}$ & - & - & $\mathrm{S}$ & - & - \\
\hline
\end{tabular}


Diversos autores salientam a importância do controle do portfolio e incorporam essa dimensão em seus modelos (COOPER; EDGETT; KLEINSCHMIDT, 1997b; ARCHER; GHASEMZADEH, 1999; PMI, 2006; RABECHINI Jr;; MAXIMIANO; MARTINS, 2005). No padrão para gerenciamento de portfolio proposto pelo PMI (2006), um dos grupos de processos refere-se ao monitoramento e controle do portfolio que envolve a revisão e publicação dos resultados do portfolio e mudança estratégica. A revisão e publicação dos resultados são responsáveis por coletar os indicadores de desempenho, publicá-los e revisar o portfolio em uma periodicidade definida, garantindo assim o alinhamento com a estratégia organizacional e a utilização adequada dos recursos. Já a mudança estratégica tem como objetivo adequar o portfolio de projetos às mudanças na estratégia organizacional. Rabechini Jr., Maximiano e Martins (2005) estabelecem um processo de revisão e controle, que busca identificar desvios na execução dos projetos do portfolio em curso, bem como propor revisões no portfolio para acomodar estes desvios. Já Cooper, Edgett e Kleinschmidt (1997b) e Archer e Ghasemzadeh (1999) propõem etapas de ajuste do portfolio. Para Cooper, Edgett e Kleinschmidt (1997b), é necessário ajustar o esquema de portões a partir da avaliação de projetos, na revisão do portfolio, mas os autores não detalham esse processo. Para Archer e Ghasemzadeh (1999), o ajuste do portfolio identifica desvios no planejamento e execução dos projetos e propõe revisões do portfolio para acomodar estes desvios, semelhante ao proposto por Rabechini Jr., Maximiano e Martins (2005).

\section{Abordagem metodológica}

O objetivo deste trabalho consiste em investigar as principais práticas de gerenciamento de portfolio adotadas e relacioná-las ao estágio de implementação do PPM na organização.

A opção metodológica adotada foi o levantamento (survey) de caráter exploratório, que é orientado para a descoberta, sem a intenção de testar ou validar hipóteses pré-estabelecidas (FREITAS et al., 2000; HAIR Jr. et al., 2005). Como há poucas informações disponíveis sobre a utilização das práticas de PPM no contexto brasileiro e como é difícil identificar respondentes elegíveis, este trabalho apresenta características de uma pesquisa exploratória com a adoção de métodos de amostragem não probabilísticos e utilização de um critério de elegibilidade para selecionar as respostas válidas a partir das informações coletadas (HAIR Jr. et al., 2005; FINK, 1995a). Este estudo também se caracteriza por um corte transversal, tendo como unidade de análise as organizações ou unidades de negócio de atuação dos respondentes (FREITAS et al., 2000; HAIR Jr. et al., 2005).
O critério de elegibilidade da amostra deste estudo são os profissionais responsáveis pela tomada de decisão nas atividades relacionadas ao PPM, que compreendem: definição de critérios e recursos, classificação, avaliação, seleção, priorização e alocação de recursos em projetos. Também se considerou como critério de elegibilidade a senioridade e o cargo dos respondentes, de tal forma que apenas os respondentes com cargos gerenciais (coordenadores, gerentes, superintendentes e diretores) foram considerados na amostra.

Devido à dificuldade em identificar estes indivíduos nas organizações, para a amostra inicial foi utilizado o método de amostragem por julgamento, expandida pelo método de amostragem bola de neve, que visa ampliar as unidades de amostra incentivando os respondentes a convidar outros respondentes responsáveis pelo gerenciamento do portfolio de projetos em outras organizações (FINK, 1995a, b; FREITAS et al., 2000; HAIR Jr. et al., 2005).

Para Hair Jr. et al. (2005), o tamanho da amostra para utilização de métodos não probabilísticos pode ser definido com base no julgamento do pesquisador e estudos anteriores. Em estudo semelhante realizado por De Reyck et al. (2005), a pesquisa foi enviada a 125 empresas e foram obtidas 31 respostas, dando um índice de efetividade de $25 \%$.

$\mathrm{O}$ instrumento de pesquisa utilizado foi um questionário autoadministrado, disponibilizado pessoalmente, em papel, aos executivos, e também via Internet. A taxa de retorno nos questionários aplicados pessoalmente foi de $100 \%$, totalizando 10 respostas obtidas desta forma. A utilização da Internet resultou em uma taxa de retorno de $25 \%$ e apenas $7 \%$ de respostas válidas, desta forma, para 300 questionários enviados por $e$-mail para potenciais respondentes, obtiveram-se apenas 21 respostas válidas.

Alguns argumentos utilizados pelos executivos que não participaram foram os seguintes: falta de tempo, não possuem autorização da empresa para fornecer informações solicitadas, não se considera a pessoa indicada para respondê-lo, entre outros.

O questionário era composto de dois blocos, um de caracterização do respondente e da empresa e o outro com questões relacionadas às práticas de PPM, seguindo as cinco dimensões da fundamentação teórica. O instrumento é composto de questões fechadas, com escalas categóricas, escalas intervalares e escalas do tipo Likert, de cinco pontos. Conforme sugere a literatura, as escalas categóricas permitem a classificação das empresas de acordo com suas características e as escalas intervalares e do tipo Likert permitem avaliar e correlacionar as respostas às diversas questões (BABBIE, 1999; HAIR Jr. et al., 2005).

O pré-teste do questionário foi feito pessoalmente com quatro executivos selecionados de uma mesma organização, na qual gestão de projetos tem alta importância para a obtenção dos objetivos estratégicos. $\mathrm{O}$ tempo de preenchimento foi medido e foi solicitado 
retorno dos respondentes quanto à clareza das questões, ao formato do questionário e à sensibilidade em fornecer os dados solicitados, conforme recomendado pela literatura (BABBIE, 1999; HAIR JR. et al., 2005). Com base no pré-teste, o questionário foi sintetizado, buscando capturar as informações mais relevantes para a pesquisa. Além disso, pesquisadores da área de gerenciamento de projetos e desenvolvimento de produto foram selecionados para a avaliação do questionário; no que concerne à aderência à literatura e aos objetivos da pesquisa, foram quatro doutorandos e um professor da Escola Politécnica da Universidade de São Paulo e da Faculdade de Administração, Economia e Contabilidade da Universidade de São Paulo.

Segundo Hair et al. (2005), os dados obtidos podem ser transformados de forma a atender aos objetivos da pesquisa e facilitar a análise. Nas questões que utilizam escala Likert, de cinco pontos, os dados serão multiplicados por 0,5 para que os valores fiquem entre -1 e +1 (DE REYCK et al., 2005). Nas respostas que utilizam a escala intervalar, que avalia a importância das práticas de PPM, os dados serão organizados como em uma escala de 0 a 1 , na qual a alternativa 'sem impacto' corresponde a 0 , a alternativa 'baixo impacto' corresponde a 0,5 e a alternativa 'alto impacto' corresponde a 1 (HAIR et al., 2005). Nas demais questões, que utilizam a escala categórica, utilizaram-se como medida de tendência central à moda (HAIR et al., 2005).

\section{Resultados da pesquisa de campo}

Foram recebidos 89 questionários respondidos, dos quais apenas 31 foram considerados válidos.
Os 58 questionários descartados foram enviados pela Internet e a caracterização do respondente não atendia ao critério de elegibilidade adotado pela pesquisa (ver seção 3).

\subsection{Caracterização da amostra: perfil das organizações}

Observou-se grande concentração de respostas de empresas oriundas do setor de Serviços Financeiros (26\%) e do setor de Serviços Especializados (23\%). Outros setores relevantes na amostra foram: o de Eletroeletrônicos (16\%), com quatro empresas que oferecem produtos para o setor de Telecomunicações e um fabricante de computadores pessoais (Personal Computer - PC) e o próprio setor de Telecomunicações (13\%), com participação das principais operadoras de telefonia móvel e fixa do País. Além destes, obteve-se duas respostas do setor Farmacêutico (6\%) e uma resposta dos setores de Alimentação, Automobilístico, Construção, Petroquímico e Siderúrgico, conforme apresentado na Figura 1.

Ainda em relação ao perfil das organizações, foi identificado que 13 (42\%) delas possuem escritório de gestão de projetos (Project Management Office PMO), 15 realizam PPM de forma padronizada (48\%), nove possuem PMO e realizam PPM de forma padronizada (29\%) e oito tem disponibilidade para realização de estudo de caso (26\%). Das oito organizações com disponibilidade para estudo de caso, quatro realizam PPM de forma padronizada. Destas quatro, duas possuem PMO. Das quatro organizações que não realizam PPM, duas possuem PMO.

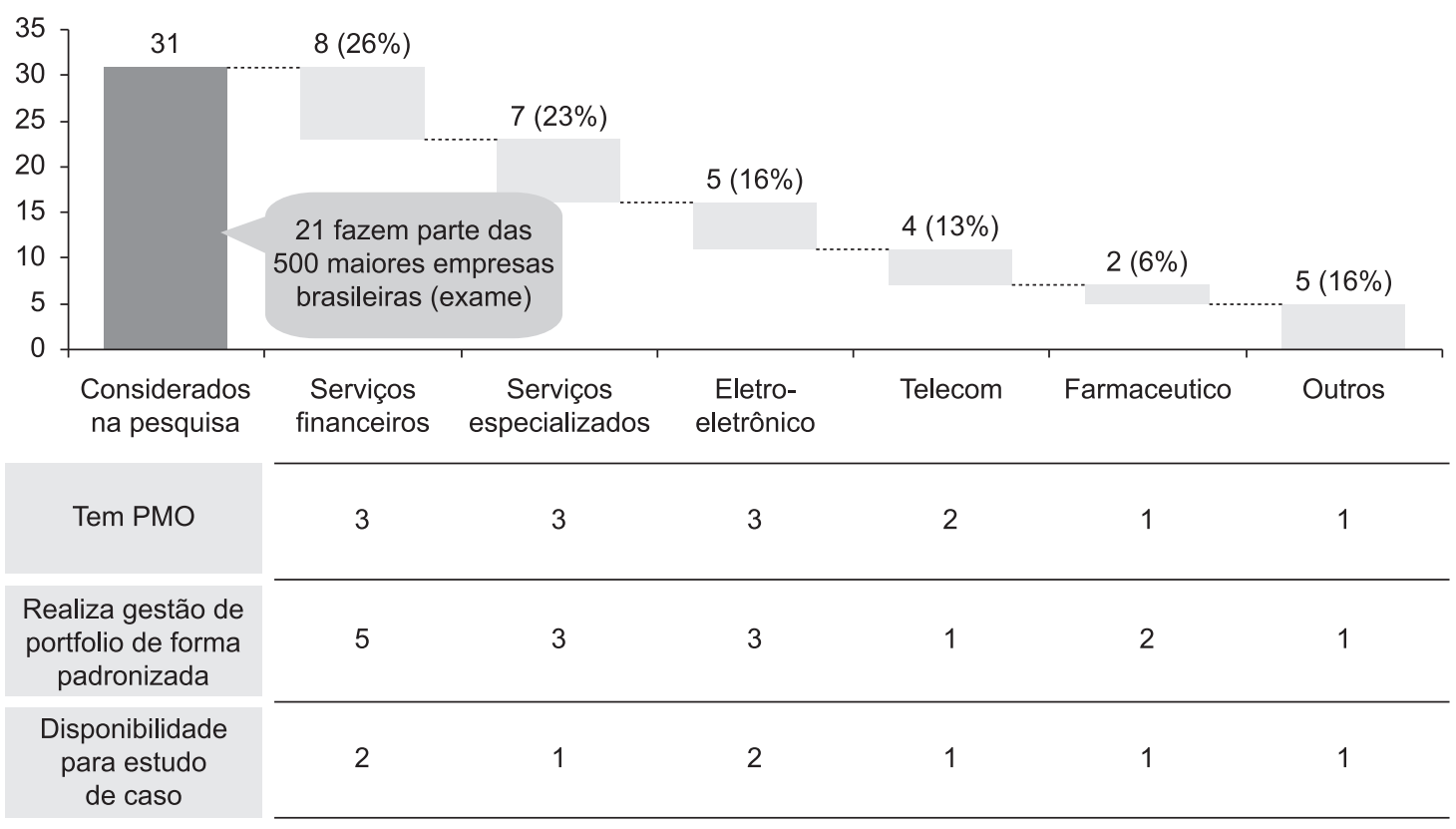

Figura 1. Distribuição das respostas por setor. 
Observou-se a predominância de estruturas matriciais para gerenciamento de projetos, com $61 \%$ das organizações (19) com menos de $25 \%$ de seus funcionários com dedicação integral a projetos e 52\% das organizações (16) com 26 a 50\% de seus funcionários com dedicação parcial a projetos.

\subsection{Caracterização da amostra: perfil dos respondentes}

A amostra foi composta em sua maioria por engenheiros (52\%), seguido por administradores/ economistas (29\%), computação/matemática (13\%) e comunicações (6\%). O maior número de respondentes atua nas áreas de Projetos/PMO (29\%) e Negócios/ Comercial (26\%), conforme esperado, uma vez que o critério de elegibilidade demandava que o respondente participasse da tomada de decisão relativa a PPM. Outras áreas de atuação representativas foram Produtos (16\%) e TI/Engenharia (13\%). As demais áreas de atuação foram Qualidade (6\%), Compras (3\%), Construção (3\%) e Operações (3\%).

Há uma grande concentração no cargo de gerente, com 22 respondentes $(71 \%)$, enquanto 7 têm cargo de diretor ou superintendente $(23 \%)$ e dois têm cargo de coordenador (6\%). Em relação ao tempo de formado, a média é 14,3 anos, bem próxima da mediana de 14 anos, com um desvio padrão de 7,5 anos. Já o tempo de empresa, é bem mais baixo, com a média em 7 anos, a mediana em 4 e o desvio padrão em 6,8 anos.

\subsection{Categoria dos projetos}

Várias organizações classificam os projetos por categorias, com uma média de 4,2 categorias de projetos por organização, com mediana de 4 e desvio padrão de 2,1 tipos de projetos. Os projetos de desenvolvimento de novos produtos e os projetos de desenvolvimento de tecnologia e sistemas de informação foram considerados por 22 organizações (71\%), enquanto os projetos de mudanças na operação ou produção por 19 (61\%), como mostra a Figura 2.

\subsection{Caracterização do Project Portfolio Management}

A caracterização do PPM foi analisada segundo um conjunto de questões apresentadas na Tabela 1 e sumarizadas na Figura 3. O respondente era questionado quanto ao grau de utilização e de impacto nos resultados para um conjunto de práticas extraídas

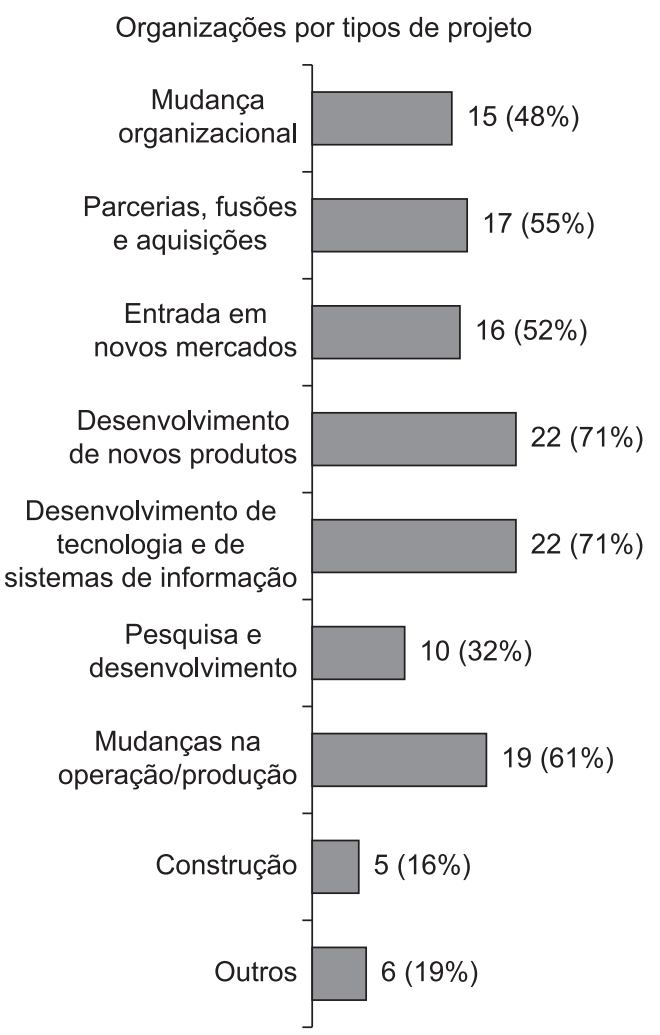

Organizações por quantidade de tipos de projeto

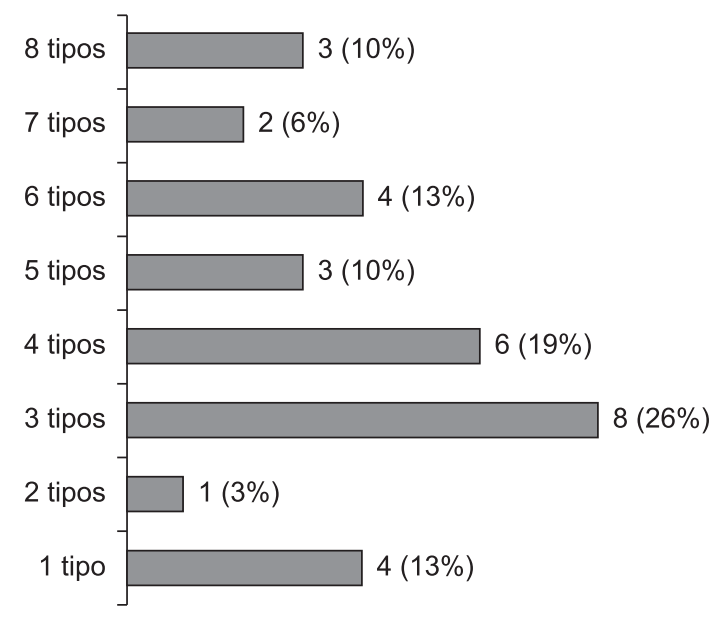

Figura 2. Categorias de projetos por organização. 


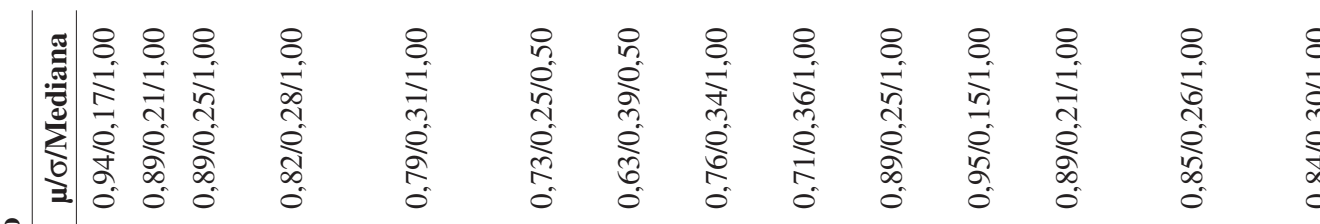

穿

苛

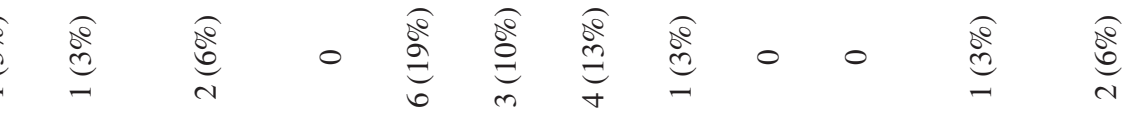

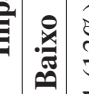

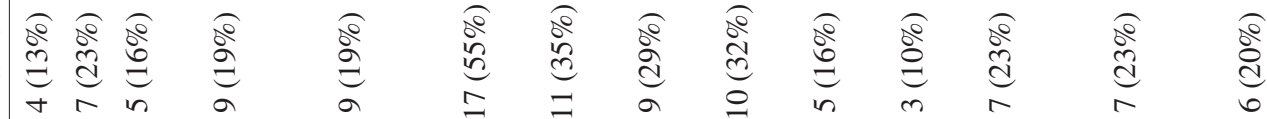

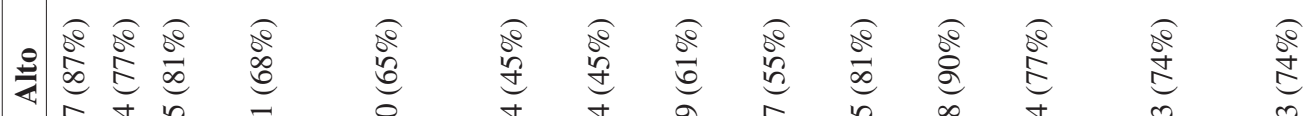

ปิ่

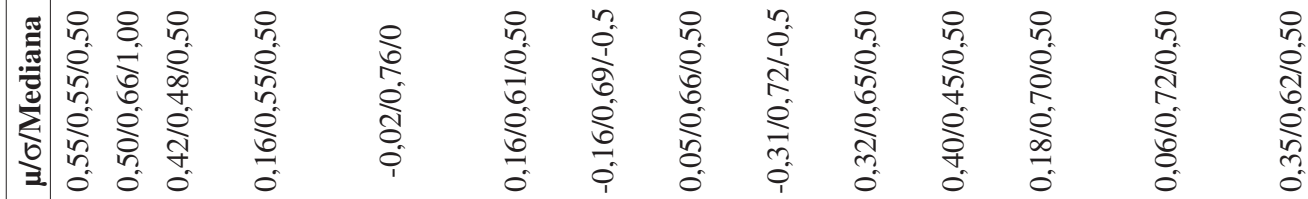

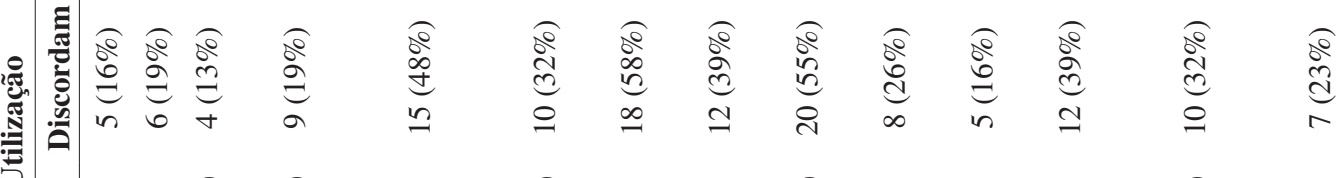

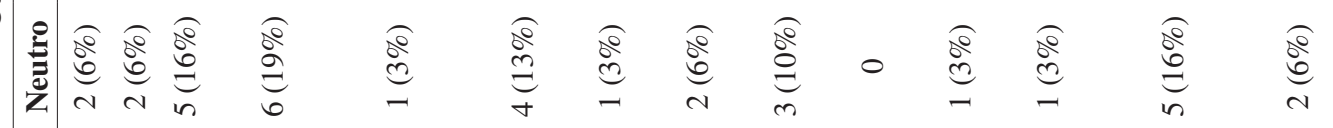

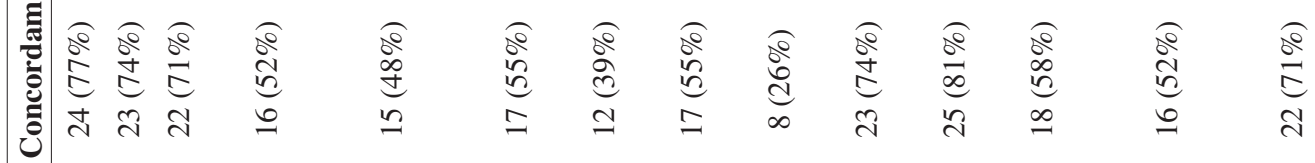

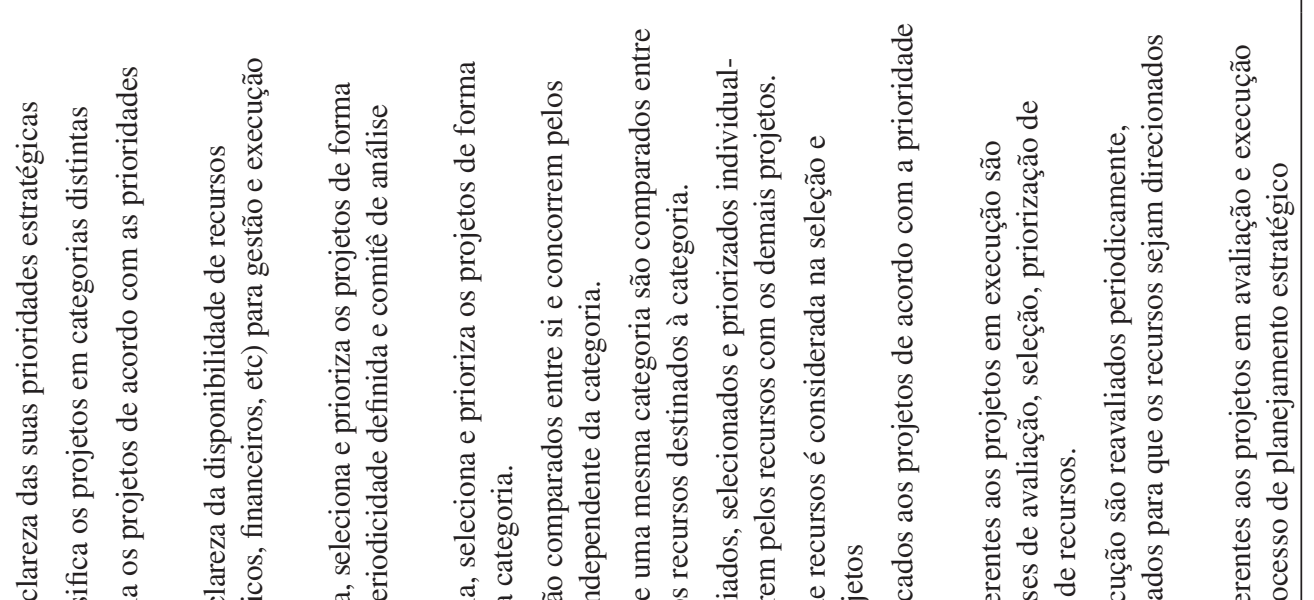

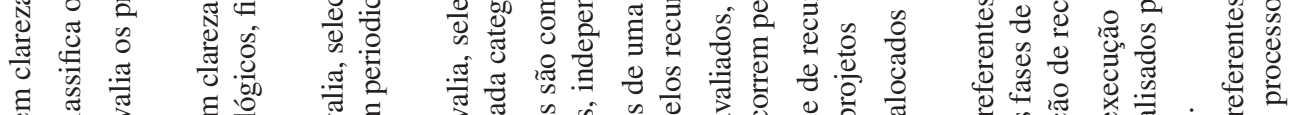

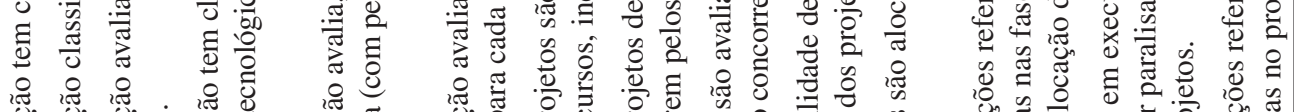


da fundamentação teórica. Embora já mencionado anteriormente, vale lembrar que a utilização foi tabulada considerando uma escala variando de $-1,0$ (discordam totalmente) a 1,0 (concordam totalmente) e a importância com uma escala intervalar de 0,0 (sem importância) a 1,0 (alta importância).

Como é possível observar na Tabela 1 e na Figura 3, as respostas que obtiveram maior grau de concordância na utilização (acima de 70\% dos entrevistados) entre os respondentes, foram às das questões $2,3,4,11$, 12 e 15. Em síntese, os respondentes julgam que suas organizações têm clareza das suas prioridades estratégicas, classificam os projetos em categorias distintas, avaliam os projetos de acordo com as prioridades estratégicas, dentro da disponibilidade de recursos e utilizam informações disponíveis referentes aos projetos em avaliação e execução no processo de planejamento estratégico. Todas estas questões também foram consideradas pelos respondentes como de alto impacto (ver Tabela 1).

As questões 13 e 14 apresentam alto índice de concordância em relação ao impacto nos resultados, no entanto houve grande dispersão dos dados quanto à utilização, o que será explorado melhor na próxima seção.

As questões 8 e 10 foram as que apresentaram discordância quanto à utilização, o que sugere que são pouco difundidas em média nas organizações estudadas. Destaca-se, no entanto, que o desvio padrão é grande, merecendo uma análise mais detalhada. As demais questões obtiveram médias próximas à neutralidade $(\mu \sim 0)$, com alto desvio padrão.

\section{Discussão dos resultados}

Para complementar a análise, as respostas das 31 organizações foram segmentadas em dois grupos, o primeiro constituído pelas organizações que realizam de forma padronizada as práticas de PPM e o segundo grupo que não utiliza. Utilizou-se para fazer a estratificação dos grupos, a resposta dada à questão 6, na qual 15 respondentes (48\%) consideram que suas organizações realizam PPM de forma padronizada (concordância parcial ou total à questão 6). A análise da Figura 4 sugere que pode haver uma diferença entre esses dois grupos de organizações.

Pode-se observar que as questões que mais discriminam os dois grupos são: 5, 7, 9, 13 e 14 . Para essas questões, o grupo que não realiza o PPM de forma padronizada apresenta um índice de utilização bem inferior (abaixo de 40\%), enquanto as empresas que realizam o PPM atingem índices de 65\% a 95\% nesse grupo de questões. Além disso, as respostas do grupo que realiza PPM apresentam menor dispersão dos resultados em todas as questões, com maior índice de concordância na maioria delas.

Além disso, observa-se que o grupo de questões $2,3,4,11,12$ e 15 , conforme já apresentado na seção anterior, apresenta forte concordância quanto à utilização para ambos os grupos, embora o grupo que realiza PPM apresente um índice de concordância ligeiramente superior ao grupo que não realiza PPM ( $\geq$ a $80 \%$ vs. entre $50 \%$ e $70 \%$, respectivamente) nas questões. Finalmente, as questões 8 e 10 foram consideradas com menor utilização por ambos os grupos (abaixo de 50\%).

Aprofundando a análise, as respostas dissonantes foram agrupadas por dimensões da fundamentação teórica, conforme a Figura 5.

Observa-se, portanto, que os principais gaps (lacunas) entre esses dois grupos estão concentrados em três dimensões. Para o grupo de organizações que não realiza o PPM de forma padronizada, há grande discordância para as dimensões de controle de

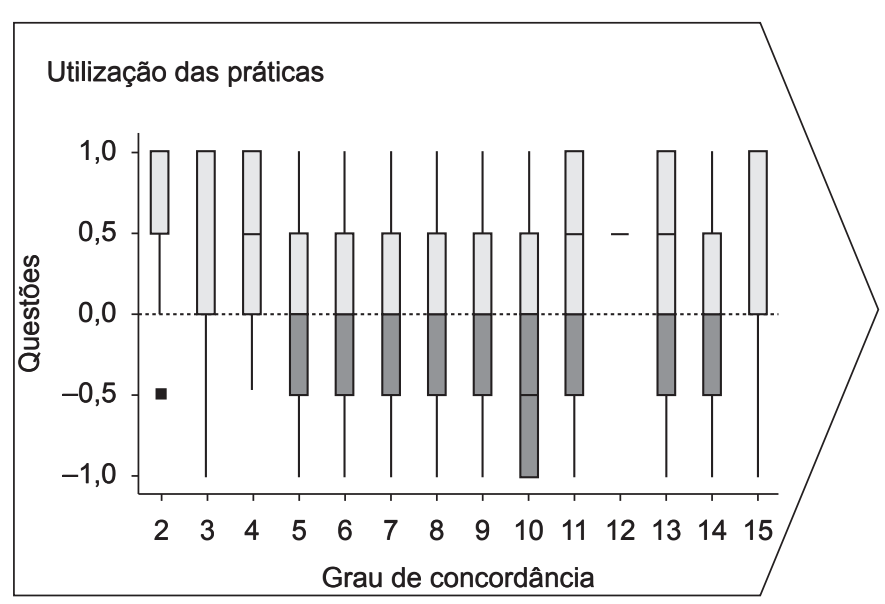

Figura 3. Distribuição das respostas para cada questão.

\section{Práticas com maior grau de utilização}

- Questão 12 (81\%): recursos são alocados de acordo com a prioridade definida

- Questão 2 (77\%): tem clareza das prioridades estratégicas

- Questão 3 (74\%): classifica os projetos em categorias distintas

- Questão 11 (74\%): disponibilidade de recursos considerada na seleção e priorização

- Questão 4 (71\%): avalia projetos de acordo com a prioridade estratégica

- Questão 15 (71\%): informações dos projetos em avaliação/execução usadas no planejamento estratégico 
portfolio (69\% de discordância), seguido de definição dos recursos e classificação dos projetos, ambas com $63 \%$ de discordância. Um pouco menos contundente, mas ainda assim com expressiva discordância nesse grupo de empresas, está a dimensão de definição dos critérios de decisão (44\% de discordância). No grupo de organizações que realiza o PPM de forma padronizada, há predominância de concordância para todas as dimensões.

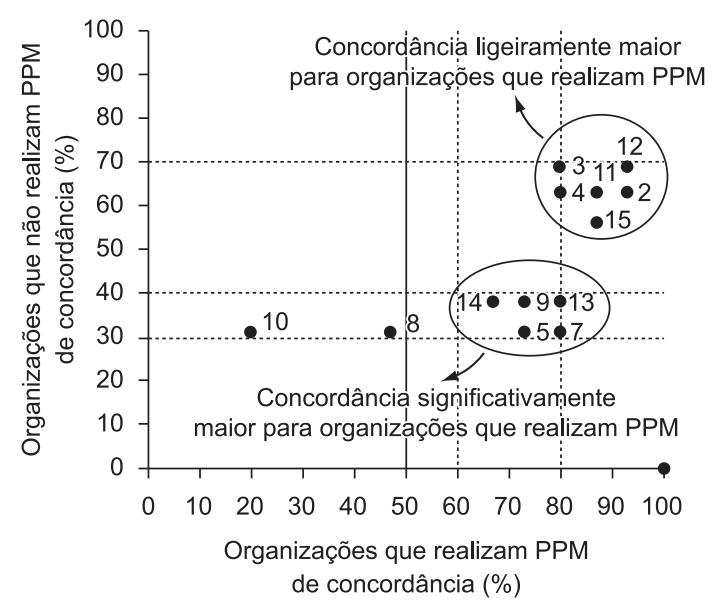

Figura 4. Análise das respostas estratificadas por grupo.
Para o grupo composto pelas 15 organizações que utilizam as práticas de PPM de forma padronizada, foi solicitado que respondessem adicionalmente a outras três questões, relacionada à periodicidade de avaliação do portfolio, participantes do comitê de avaliação e as ferramentas, cujo resultado está na Figura 6. Das 15 organizações, 6 (40\%) adotam periodicidade mensal ou trimestral de avaliação do portfolio, 3 realizam semestralmente, 3 anualmente e 3 realizam a cada 2 ou 3 anos.

Em relação à composição do comitê de avaliação do portfolio, a maior parcela é de diretores e superintendentes, que compõem o comitê em $80 \%$ das organizações estudadas. Os gerentes de projeto participam do comitê em $60 \%$ das organizações, o CEO em $40 \%$ e os gerentes funcionais em $33 \%$. Apenas uma das organizações respondentes identificou a participação do PMO no comitê.

Já em relação às ferramentas de avaliação utilizadas, os métodos financeiros foram relatados por 13 das 15 organizações $(87 \%)$. Os modelos de ponderação são utilizados em 7 (47\%), os checklists em 4 (27\%), diagramas de bolha e programação linear para ajuste dos recursos em 2 (13\%). Os métodos de opções reais e AHP não são utilizados por nenhuma das organizações, enquanto 3 utilizam métodos desenvolvidos pelas próprias organizações (20\%).

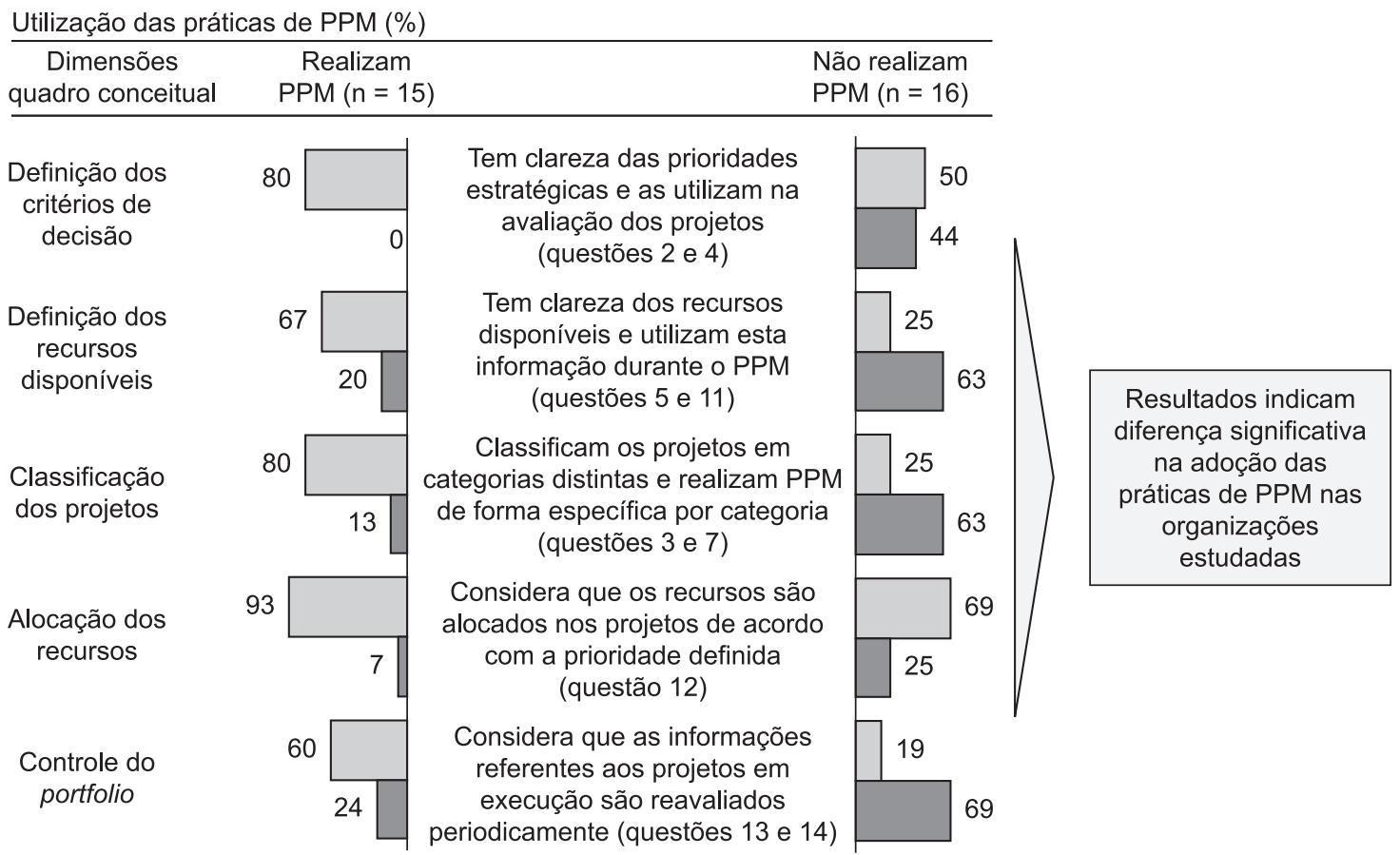

Concordam com ambas as questões $\square$ Discordam de pelo menos uma das questões

Figura 5. Análise dos dois grupos face às dimensões de PPM. 


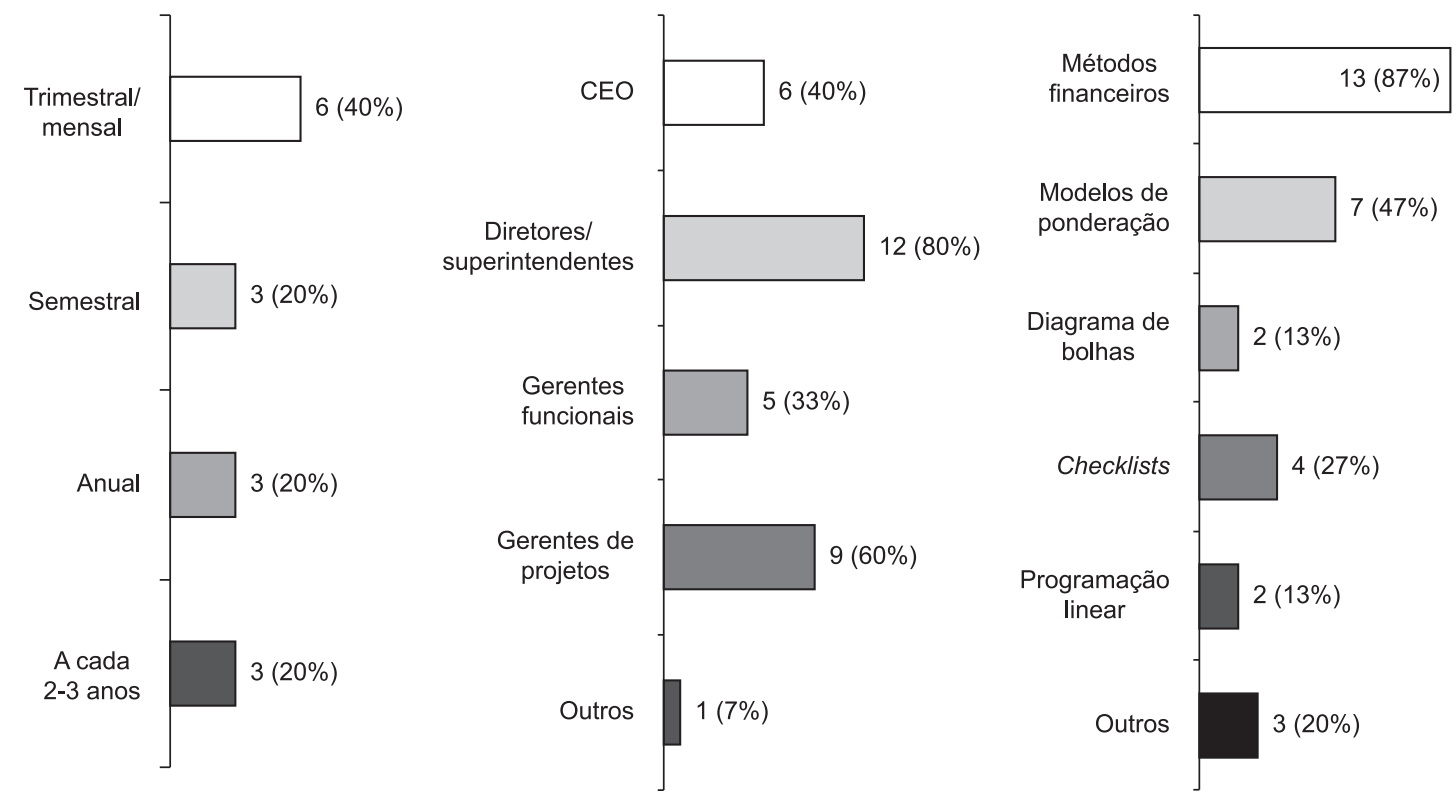

Figura 6. Periodicidade, participantes e ferramentas do PPM.

\section{Conclusões}

As cinco dimensões de PPM extraídas do quadro teórico com base nos modelos Wheelwright e Clark (1992), Cooper, Edgett e Kleinschmidt (1997) e Archer e Ghasemzadeh (1999), Rabechini Jr., Maximiano e Martins (2005) e PMI (2006) mostraram forte aderência às organizações que realizam o PPM de forma padronizada.

Por outro lado foi possível observar fortes discrepâncias entre as empresas que realizam o PPM de forma padronizada daquelas que não realizam. Os principais gaps entre os grupos estão relacionados a três dimensões, quais sejam: controle de portfolio, definição dos recursos e classificação dos projetos. Nestas dimensões, o grupo de organizações que não realiza o PPM de forma padronizada apresenta forte discordância (superior a 60\%) enquanto o grupo que realiza o PPM apresenta forte concordância (superior a $65 \%$ ).

De forma mais detalhada, observou-se que o que mais discrimina os dois grupos são os aspectos relacionados clareza da disponibilidade de recursos (questão 5), avaliação, seleção e priorização dos projetos por categoria (questão 7), comparação e concorrência dos projetos pelos recursos destinados à categoria (questão 9), as informações dos projetos em execução são consideradas na análise (questão 13), os projetos em execução são reavaliados periodicamente (questão 14). Para essas questões o grupo que não realiza o PPM de forma padronizada apresenta um índice de utilização bem inferior ao das empresas que realizam o PPM.

A periodicidade de avaliação (revisão) do portfolio foi surpreendente, dado que a literatura advoga horizonte de médio/longo prazo devido à natureza estratégica das decisões de portfolio. No entanto, os resultados apontam para a periodicidade mensal e trimestral dessas análises. Este aspecto precisa ser aprofundado em estudo futuros, pois é provável que esteja fortemente ligado à tipologia de projetos que a organização desenvolve.

Os principais stakeholders que participam do processo decisório do PPM, com atuação no comitê de avaliação do portfolio são os diretores e superintendentes (80\%), os gerentes de projeto $(60 \%)$, o CEO (40\%) e os gerentes funcionais (33\%). Destaca-se que, em apenas uma das organizações, o PMO participa do comitê, o que demonstra o perfil mais tático que estratégico dos PMOs em empresas brasileiras (Rodrigues, Rabechini Jr. e Csillag, 2006).

As limitações deste estudo são decorrentes das escolhas metodológicas. Ao optar por uma amostragem não probabilística, os resultados desta pesquisa não poderão ser generalizados. Além disso, a amostra é constituída predominantemente por alunos de MBA, o que imprime viés na análise (HAIR Jr. et al., 2005). No entanto, foi possível identificar indícios das práticas adotadas pelas organizações e de lacunas que devem ser equacionadas para uma melhor prática de gerenciamento de portfolio de projetos nas organizações. 


\section{Referências}

ARCHER, N. P.; GHASEMZADEH, F. An integrated framework for project portfolio selection. International Journal of Project Management. v. 17, n. 4, p. 207-216, 1999.

ARCHER, N. P.; GHASEMZADEH, F. Project portfolio selection: a review and a suggested integrated approach. Innovation Research Working Group Working Paper, n. 46, p. 1-19, 1996.

ARCHIBALD, R. D. Managing high-technology programs and projects. 2. ed. New York: Wiley, 1992.

ARDITI, D.; SINGH, S. Selection criteria for commercially available software in construction accounting. International Journal of Project Management, v. 9, n. 1, p. 39-44, 1991.

BABBIE, E. Métodos de pesquisa de survey. Belo Horizonte: UFMG, 1999.

BERTOLINI, M.; BRAGLIA, M.; CARMIGNANI, G. Application of the AHP methodology in making a proposal for a public work contract. International Journal of Project Management, v. 24, n. 5, p. 422-430, 2006.

CARVALHO, M. M.; RABECHINI Jr., R. Construindo competências para gerenciar projetos: teoria e casos. São Paulo: Atlas, 2005.

CASTRO, H. G.; CARVALHO, M. M. Critical issues in project management best practices implementation: multiple cases in Brazilian telecommunication companies. In: ANNUAL CONFERENCE OF POMS, 17., 2006, Boston. Anais... Boston: POMS, 2006. p. 1-16.

CLELAND, D. I. The strategic context of projects. In: DYE, L. D.; PENNYPACKER, J. S. Project portfolio management: selecting and prioritizing projects for competitive advantage. West Chester: Center for Business Practices, 1999.

COMBE, M. W. Project prioritization in a large functional organization. In: ANNUAL PROJECT MANAGEMENT INSTITUTE SEMINARS E SYMPOSIUM, 4., 1998. Proceedings... Newtown Square: Project Management Institute, 1998.

COOPER, R. G.; EDGETT, S. J.; KLEINSCHMIDT, E. J. Best practices for managing R\&D portfolios. Research Technology Management, v. 41, n. 4, p. 20-33, 1998.

COOPER, R. G.; EDGETT, S. J.; KLEINSCHMIDT, E. J. New product portfolio management: practices and performance. Journal of Product Innovation Management, v. 16, n. 4, p. 333-351, 1999.

COOPER, R. G.; EDGETT, S. J.; KLEINSCHMIDT, E. J. Portfolio management in new product development: lessons from the leader - I. Research Technology Management, v. 40, n. 5, p. 16-19, 1997a.

COOPER, R. G.; EDGETT, S. J.; KLEINSCHMIDT, E. J. Portfolio management in new product development: lessons from the leaders - II. Research Technology Management, v. 40, n. 5, p. 43-52, 1997 b.

COOPER, R. G.; EDGETT, S. J.; KLEINSCHMIDT, E. J. Portfolio management: fundamental to new product success. [S.1.]: Product Development Institute, 2001a. (Working Paper, 12).
COOPER, R. G.; EDGETT, S. J.; KLEINSCHMIDT, E. J. Portfolio management for new product development: results of an industry practices study. R\&D Management, v. 31, n. 4, p. 361-380, 2001b.

DE REYCK, B. et al. The impact of project portfolio management on information technology projects. International Journal of Project Management, v. 23, n. 7, p. 524-537, 2005.

DIETRICH, P.; LEHTONEN, P. Successful management of strategic intentions through multiple projects - reflections from empirical study. International Journal of Project Management, v. 23, n. 5, p. 386-391, 2005.

DYE, L. D.; PENNYPACKER, J. S. Project portfolio management and managing multiple projects: two sides of the same coin. In: PROJECT MANAGEMENT INSTITUTE ANNUAL SEMINARS \& SYMPOSIUM, 2000, Houston, Texas. USA. Proceedings... Maryland: Project Management Institute, 2000.

DYE, L. D.; PENNYPACKER, J. S. Project portfolio management: selecting and prioritizing projects for competitive advantage. West Chester: Center for Business Practices, 1999.

ENGWALL, M.; JERBRANT, A. The resource allocation syndrome: the prime challenge of multi-project management? International Journal of Project Management, v. 21, n. 6, p. 403-409, 2003.

FINK, A. How to sample in surveys. Thousand Oaks: Sage Publications, 1995a.

FINK, A. The survey handbook. Thousand Oaks: Sage Publications, 1995b.

FREITAS, H. et al. O método de pesquisa survey. Revista da administração, v. 35, n. 3, p. 105-112, 2000.

GREMILLION, L. L.; PYBURN, P. Breaking the systems development bottleneck. Harvard Business Review, v. 61, n. 2, p. 130-138, 1983.

HAIR Jr., J. F. et al. Fundamentos de métodos de pesquisa em administração. Porto Alegre: Bookman, 2005.

HAMILTON, A. Considering value during early project development: a product case study. International Journal of Project Management, v. 20, n. 2, p. 131-136, 2002.

JEFFERY, M.; LELIVELD, I. Best practicies in it portfolio management. MIT Sloan Management Review, v. 45, n. 3, p. 41-50, 2004.

JOLLY, D. The issue of weightings in technology portfolio management. Technovation, v. 23, n. 5, p. 383-391, 2003.

KENDALL, G. I.; ROLLINS S. C. Advanced project portfolio management and the PMO: multiplying ROI at warp speed. Fort Lauderdale: Ross Publishing, 2003.

KERZNER, H. Gestão de projetos: as melhores práticas. Porto Alegre: Bookman, 2002.

KESSLER, E. H.; CHAKRABARTI, A. K. Innovation speed: a conceptual model of context, antecedents, and outcomes. Academy of Management, v. 21, n. 4, p. 1143-1191, 1996.

KRUGLIANSKAS, I. Planejamento do centro de tecnologia empresarial cativo. In: VASCONCELLOS, E. (Ed.). Gerenciamento da tecnologia: um instrumento para a 
competitividade empresarial. São Paulo: Edgar Blucher, 1992.

LEVINE, H. A. Project portfolio management: a song without words? PM Network. Maryland: Project Management Institute, 1999.

MAHDI, I. M.; ALRESHAID, K. Decision support system for selecting the proper project delivery method using analytical hierarchy process (AHP). International Journal of Project Management, v. 23, n. 7, p. 564-572, 2005.

MCFARLAN, F. W. Portfolio approach to information systems. Harvard Business Review, v. 59, n. 5, p. 142-151, 1981.

MCFARLAN, F. W.; MCKENNEY, J. L.; PYBURN, P. The information archipelago - plotting a course. Harvard Business Review, v. 61, n. 4, p. 91-100, 1983.

MERRIFIELD, D. B. How to select successful R\&D projects. Management Review, v. 67, n. 12, p. 25-39, 1978.

MIKKOLA, J. H. Portfolio management of R\&D projects: implications for innovation management. Technovation, v. 21, n. 7, p. 423-435, 2001.

PADOVANI, M. et al. Looking for the right criteria to define projects portfolio: multiple case study analysis.
Product: Management \& Development, v. 6, n. 2, p. 127-134, 2008.

PROJECT MANAGEMENT INSTITUTE - PMI. The standard for portfolio management. Maryland: Project Management Institute, 2006.

RABECHINI Jr., R.; MAXIMIANO, A. C. A.; MARTINS, V. A. A adoção de portfolio como uma alternativa gerencial: o caso de uma empresa prestadora de serviço de interconexão eletrônica. Revista de Produção, v. 15, n. 3, p. 416-433, 2005.

RODRIGUES, I.; RABECHINI Jr., R.; CSILLAG, J. M. Os escritórios de projetos como indutores de maturidades em gestão de projetos RAUSP. Revista de Administração, v. 41, n. 3, p. 273-287, 2006.

SHARPE, P.; KEELIN, T. How SmithKline Beecham makes better resource-allocation decisions. Harvard Business Review, v. 76, n. 2, p. 45-53, 1998.

SHENHAR, A. J. One Size does not fit all projects: exploring classical contingency domains. Management Science, v. 47, n. 3, p. 394-414, 2001.

WHEELWRIGHT, S. C.; CLARK, K. B. Creating project plans to focus product development. Harvard Business Review, v. 70, n. 2, p. 70-83, 1992. 